\begin{tabular}{|c|c|c|c|}
\hline Article Info & RESEARCH ARTICLE & ARAŞTIRMA MAKALESİ & \\
\hline Title of Article & \multicolumn{2}{|c|}{$\begin{array}{l}\text { Stone Decay in Sultan Hamza-i Kebir } \\
\text { Mosque }\end{array}$} & \\
\hline $\begin{array}{l}\text { Corresponding } \\
\text { Author }\end{array}$ & \multicolumn{2}{|l|}{$\begin{array}{l}\text { Dr.Öğr.Üyesi Şefika ERGİN } \\
\text { Dicle Üniversitesi, sefika@dicleedu.tr }\end{array}$} & 14 \\
\hline $\begin{array}{l}\text { Received Date } \\
\text { Accepted Date }\end{array}$ & \multicolumn{2}{|l|}{$\begin{array}{l}19.05 .2021 \\
12.06 .2021\end{array}$} & \\
\hline DOI NUMBER: & \multicolumn{2}{|l|}{ https://doi.org/10.35674/kent.931428 } & \\
\hline Author / Authors & $\begin{array}{l}\text { Şefika ERGIN } \\
\text { Büssra KARAHAN } \\
\text { Murat DAL }\end{array}$ & $\begin{array}{l}\text { ORCID: } 0000-0002-7287-7886 \\
\text { ORCID: } 0000000329430509 \\
\text { ORCID: } 0000000153301868\end{array}$ & \\
\hline How to Cite & \multicolumn{2}{|c|}{$\begin{array}{l}\text { ERGIN Ş., KARAHAN B. and DAL M. (2020). Sultan Hamza-i Kebir Cami’sinde } \\
\text { Görülen Taş Bozunmaları, Kent Akademisi, Volume, 14, Issue2, 414-427. }\end{array}$} & $\begin{array}{l}\text { Kent Akademisi } \\
\text { Urban Academy }\end{array}$ \\
\hline
\end{tabular}

\title{
Sultan Hamza-i Kebir Cami'sinde Görülen Taş Bozunmaları
}

\begin{abstract}
:
Natural stone was used as the main material in most of the architectural traditional buildings. The most important factor in preserving cultural structures until today is the durability of the stone. Natural stones used in architectural buildings are affected by atmospheric weather conditions, and over time, deterioration occurs in building facade stones due to physical, chemical, biological and human effects. In this study, the deterioration observed in the Sultan Hamza-i Kebir Mosque in the Central district of Mardin province was examined. The deteriorations that occur in the mosque are classified and illustrated with visuals. When the structure was examined, it was seen that degradation caused by physical, chemical, biological and human effects is common. Physical degradation of the structure: crack-fracture formation, pitting, surface loss, abrasion and joint discharge; as chemical degradation: surface contamination, salinization and discoloration; Also seen as biological degradation: examples of plant formation and microorganism formation. In addition, degradation is observed due to human effects such as misuse, faulty repair, lack of maintenance. The aim of the article is to reveal the problems of Sultan Hamza-i Kebir Mosque, one of our cultural heritage, to offer solutions and to ensure that the building is transferred to future generations in a healthy way while preserving its originality.
\end{abstract}

KEYWORDS: Mardin, Traditional Stone Structures, Sultan Hamza-İ Kebir Mosque, Stone Decays, Types Of Decay

ÖZ:

Geleneksel yapıların çoğunda ana malzeme olarak doğal taş kullanılmıştır. Kültürel yapıların günümüze kadar korunmasında en önemli faktör taşın dayanıklılık özelliğidir. Yapılarda kullanılan doğal taşlar atmosferik hava koşullarından etkilenmekte, zamanla yapının cephesindeki taşlarda fiziksel, kimyasal, biyolojik ve insan etkilerinden kaynaklı bozunmalar meydana gelmektedir. Bu çalışmada Mardin ili Merkez ilçesindeki Sultan Hamza-i Kebir Camii'nde görülen bozunmalar irdelenmiştir. Cami'de meydana gelen bozunmalar sinıflandırılmış ve görsellerle örneklendirilmiştir. Yapı incelendiğinde fiziksel, kimyasal, biyolojik ve insan etkilerinden kaynaklı bozunmaların

\footnotetext{
${ }^{1}$ Dicle Üniversitesi,Mimarlık Fakültesi, Mimarlık Bölümü, sefika@dicle.edu.tr

${ }^{2}$ Dicle Üniversitesi,Mimarlık Fakültesi, Fen bilimleri Enstitüsü, Mimarlık ABD, karahannbusraa@gmail.com

${ }^{3}$ Munzur Üniversitesi, Güzel Sanatlar, Tasarım ve Mimarlık Fakültesi, Mimarlık Bölümü, muratdal1122@gmail.com
} 
yaygın olduğu görülmüştür. Yapıda fiziksel bozunma olarak: çatlak-kırık oluşumu, oyuklanma, yüzey kaybı, aşınma ve derz boşalması; kimyasal bozunma olarak: yüzey kirliliği, tuzlanma ve renk değişimi; biyolojik bozunma olarak da bitki oluşumu ve mikroorganizma oluşumu örnekleri görülmektedir. Ayrıca kötü kullanım, hatalı onarım, bakımsızlık gibi insan etkilerinden kaynaklı bozunmalar mevcuttur. Makalenin amacı, kültürel miraslarımızdan biri olan Sultan Hamzai Kebir Camii’nin sorunlarını ortaya koymak, çözüm önerileri sunmak ve yapının özgünlüğünü koruyarak sağlıklı bir şekilde gelecek kuşaklara aktarılmasına katkı sağlamaktır.

ANAHTAR KELIMELER: Mardin, Geleneksel Taş Yapılar, Sultan Hamza-İ Kebir Cami, Taş Bozunmaları, Bozunma Çeşitleri

\section{GÍRISș:}

Doğal taşlar, yüzyıllardır mimari yapılarda kullanılan ve yapıların kalıcılığında etkili olan malzemelerdendir. Doğal taşlar, yapı içerisinde birçok farklı alanda kullanılır. Tarihi yapılara bakıldığında yapı malzemesi olarak kolon, taşıyıcı duvar, cephe ve döşemelerde tercih edildiği gözlemlenmektedir (Hasbay ve Hattap, 2017).

Yapı malzemeleri başta çevre ve zaman koşulları olmakla birlikte birçok etki sebebiyle çeşitli bozunmalara maruz kalır. Bu duruma başka bir deyişle alterasyon da denebilir. Geleceğimize 1şı tutan değerli tarihi yapılarımız ne yazık ki birçok nedenden kaynaklı doğal yapısını kaybetmekle karşı karşıya kalmaktadır (MEB, 2013; Öcal ve Dal, 2012).

Önemli tarihi eserlerin bozunmalarına engel olabilmek için öncelikle bozunmanın ana kaynağını belirlemek gerekir. Tarihi yapıların bozunma nedenlerini erken ve doğru tespit etmek yapıların ömrünü uzatmasına yardım eder (MEB, 2013).

Mardin yüzyıllarca farklı uygarlık, kültür, etnik dil, din ve kökene ait insanları huzur içinde bir arada yaşadığı eski bir kenttir (Alioğlu, 2000). Mardin'e yerleşen uygarlıklar şehirde birçok dini yapılar inşa etmiştir. Günümüze kadar gelen yapılardan bazıları hala kullanılmaktadır (Uyar,2019). Kentin kültür mirası olan yapılar içinde ibadet yapısı olan camiler ayrı bir öneme sahiptir. Bu yapılardan biri Sultan Hamza-i Kebir Cami’dir.

Bu çalışma, Mardin'de bulunan Sultan Hamza-i Kebir Cami'de meydana gelen taş bozunmalarının incelenmesine yöneliktir. Geçmişten günümüze kalan bu önemli tarihi eserimizde meydana gelen bozunmaların ve sebeplerinin tespit edilmesi, alınacak tedbirler ile yeni hasarların önlenebilmesi hedeflenmiştir. Bunun yanı sıra yapıda meydana gelen mevcut bozunma sorunlarının ve bu sorunlara neden olan etkenlerin belirlenmesi, çözüm önerilerinin sunulabilmesi, yapının özgünlüğünün korunarak sağlıklı bir şekilde gelecek kuşaklara aktarılması bakımından önemlidir.

\section{MATERYAL VE METOD}

Çalışmada, Mardin ili sınırları içinde bulunan Sultan Hamza-i Kebir Cami'nde meydana gelen taş bozunmaları ele alınmıştır. $\mathrm{Bu}$ amaçla öncelikle yapıda gözlemler yapılmış, tespit edilen farklı bozunma türleri tespit edilip, fotoğraflanarak belgelenmiştir. Bozunma türleri; yapıda oluşan fiziksel bozunma, kimyasal bozunma, biyolojik bozunma, İnsan etkileri ile olan bozunmalar olmak üzere 4 başlıkta kategorize edilmiştir. Yapıda fiziksel bozunma olarak: çatlak-kırık oluşumu, oyuklanma, yüzey kaybı, aşınma ve derz boşalması; kimyasal bozunma olarak: yüzey kirliliği, tuzlanma ve renk değişimi; biyolojik bozunma olarak da bitki oluşumu ve mikroorganizma oluşumu alt kategorilerine göre örneklendirilmiştir.

\section{MARDIN İLİ MERKEZ İLÇESINDEKİ SULTAN HAMZA-İ KEBİR CAMISSININ MIMARİ ÖZELLIKKLERI}

\subsection{Yapının Konumu}

Mardin, ilk uygarlığın olduğu yer olarak tahmin edilen Mezopotamya bölgesinde bulunur. Mardin, Türkiye’nin güneydoğusunda yer alır. Mardin'in komşularına bakıldığında batısında Şanlıurfa, doğusunda Şırnak kuzeyinde Diyarbakır ve Batman, kuzeydoğusunda Siirt ve güneyinde Suriye yer alır (Şekil 1). Bölgede nemli Akdeniz etkisiyle karasal iklim hakimdir. Mardin'in yüksekliğinden dolayı kışları sert geçer, düzlük alanda ise yazları yine aynı sebepten dolayı daha 1lımandır (Kaya, 2015; Karagülle, 2009). 


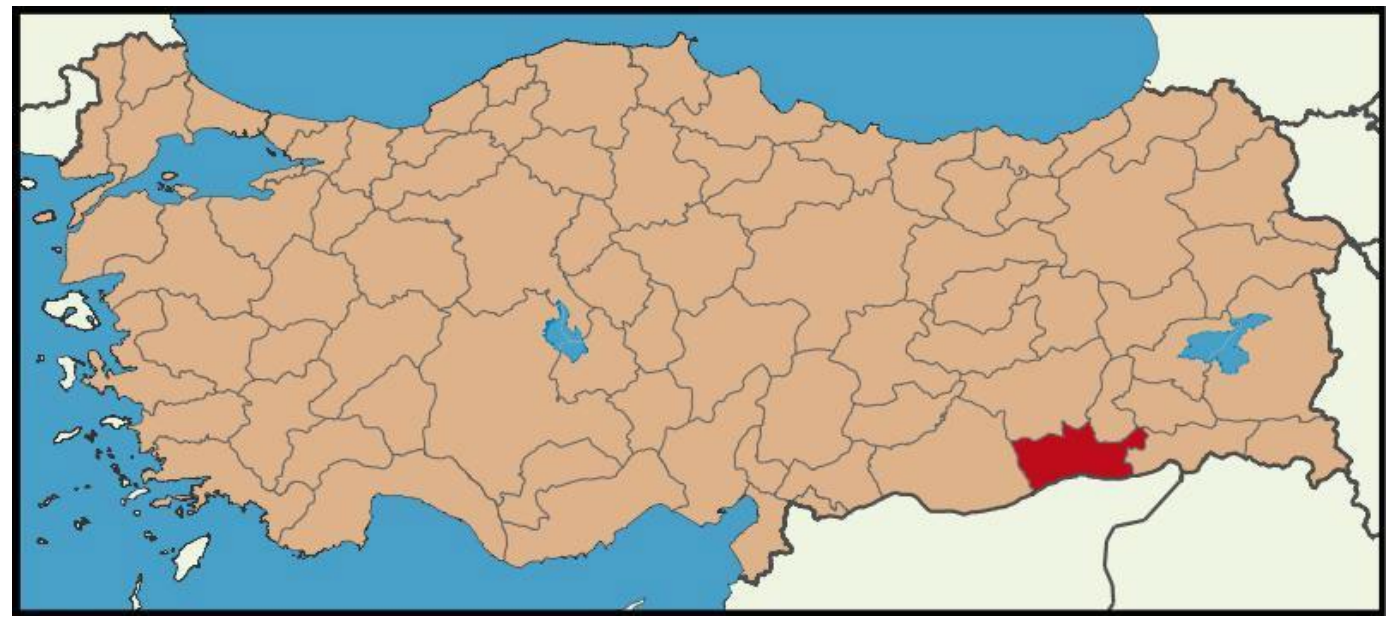

Şekil 1. Mardin ilinin konumu (URL-1, 2020)

Sultan Hamza-i Kebir Cami; Mardin'in Savurkapı Mahallesi, Anayol Caddesi’nde, Meydan başı yakınında yolun güney tarafında konumlanmaktadır. Yapının kayıtlı olduğu numara 158 ada, 2 parseldir. Yapı dört yana bakar şekilde prizmal bir kütle şeklinde inşa edilmiştir (Yeşilbaş, 2014).

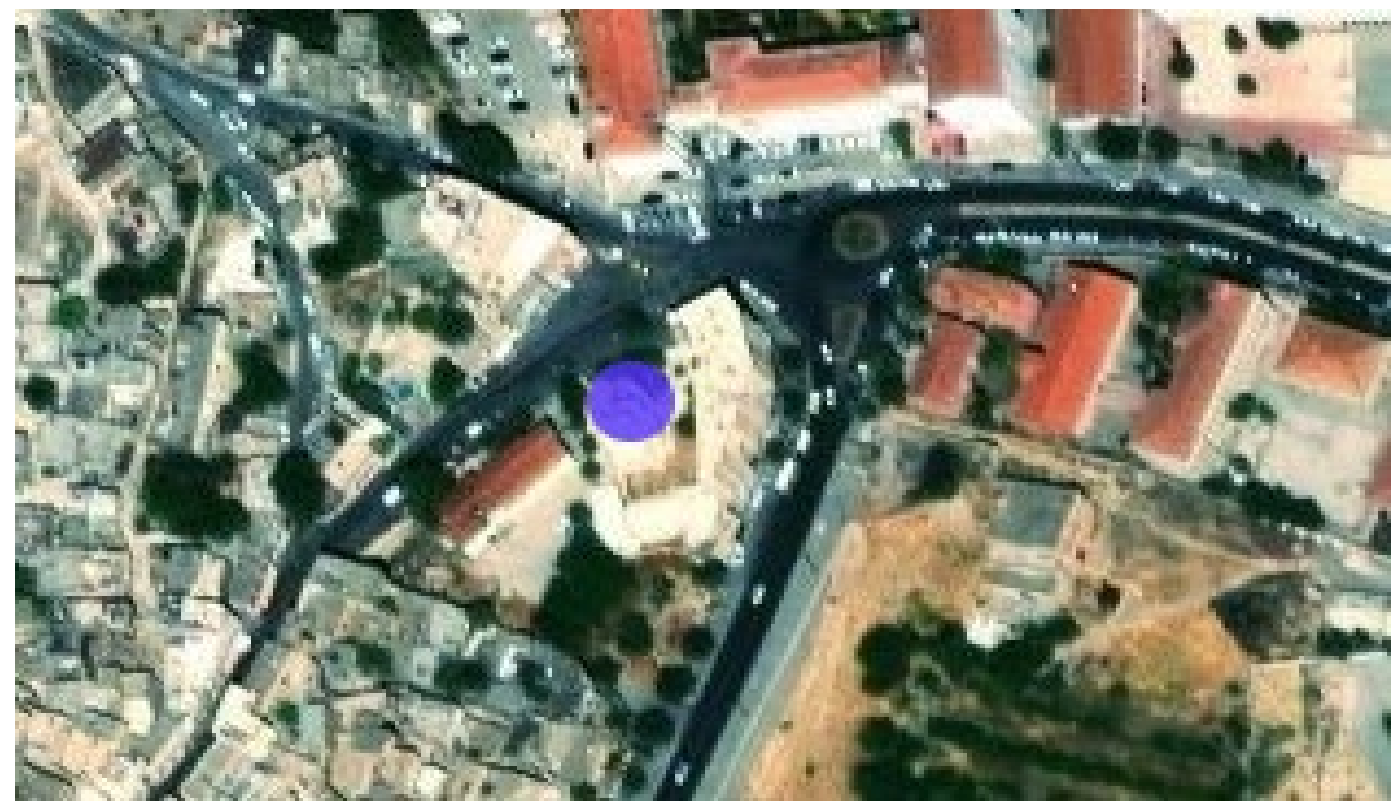

Şekil 2. Sultan Hamza-i Kebir Cami konumu (URL-2)

\subsection{Yapının Tarihçesi}

Sultan Hamza-i Kebir Cami, Akkoyunlu Hamza Bey’e ait olduğu bildirilen ve bugün beton camekanı ile kesilmiş kitabesinden anlaşıldığına göre (1438-1439) yıllarında inşa edilmiştir. Akkoyunlu Hamza Kara Yülük Osman tarafından yaptırılmıştır (1434-1444). Günümüzde mevcutta sadece Hamza Bey'in türbesinin kalıntısı bulunmaktadır. Abdulgani Efendi'nin kayıtlarında daha önce burada bir zaviyenin bulunduğu ancak şu an mescit olarak kullanıldığı yazılmaktadır. Altun, günümüzde kullanılan mescit bölümünün, aslında türbe bölümünün değiştirilmesiyle ortaya çıktığını söylemektedir. Yapının XVIII. yüzyılda mescit olarak kullanılmaya devam ettiğini görüyoruz. Bu yapının çevresinde zaviyenin kurulup kurulmadığı hakkında kaynaklara bakıldığında hiçbir bilgiye rastlanmamaktadır. İncelediğimiz türbenin Sultan Hamza'nın vefatından önce yapılmış olduğu ve vasiyeti dolayısıyla Diyarbakır'da ölmesine rağmen Mardin'de gömülmüş olduğu bilgisi bulunmaktadır. N. Göyünç binanın 1932 yılında baruthane olarak kullanılması nedeniyle yapıya yaklaşmanın yasak olmasından ötürü A. Gabriel tarafından sadece 1435-1444 senelerinin 
belirtildiğini, kitabesinin saptanamadığını ifade etmektedir. Avludaki mezar, mezar taşının metnine göre Sultan Hamza'ya ait olduğu düşünülmektedir. Hamza-i Kebir Zaviyesi, inşa edildiğinde zaviye-tekke işleviyle yapılmıştır. Günümüzde türbe kısmı kalmıştır. Fakat türbe kısmı da mescit olarak kullanılmaktadır (Uyar, 2019). Yapıya 1995 yılında betonarme bir minare eklenmiştir. Ancak minare yapının tarihi dokusuna uygun olmadığı için yıkılıp tarih dokusu ve mimari formuna uygun bir şekilde yeniden inşa edilmiştir.

\subsection{Mimari Özellikleri}

Yapı, haçvari bir arsa üzerine dört yöne uzanır vaziyette planlanmıştır (Şekil 3). Yapının, sekizgen kasnağa oturan dıştan nervürlü kubbe ile örtülü olması Akkoyunlu mimarisinin Mardin’e özgü gelenekselleşmiş bir detayıdır. Kubbenin her bir dilimine sağır kemerlerle hareket katarak kasnağa geçişi sağlanmış, sekizgen kasnağın dört köşeden üçgen çıkıntılarla çatıya doğru uzandığı görülmektedir (Yeşilbaş, 2014).

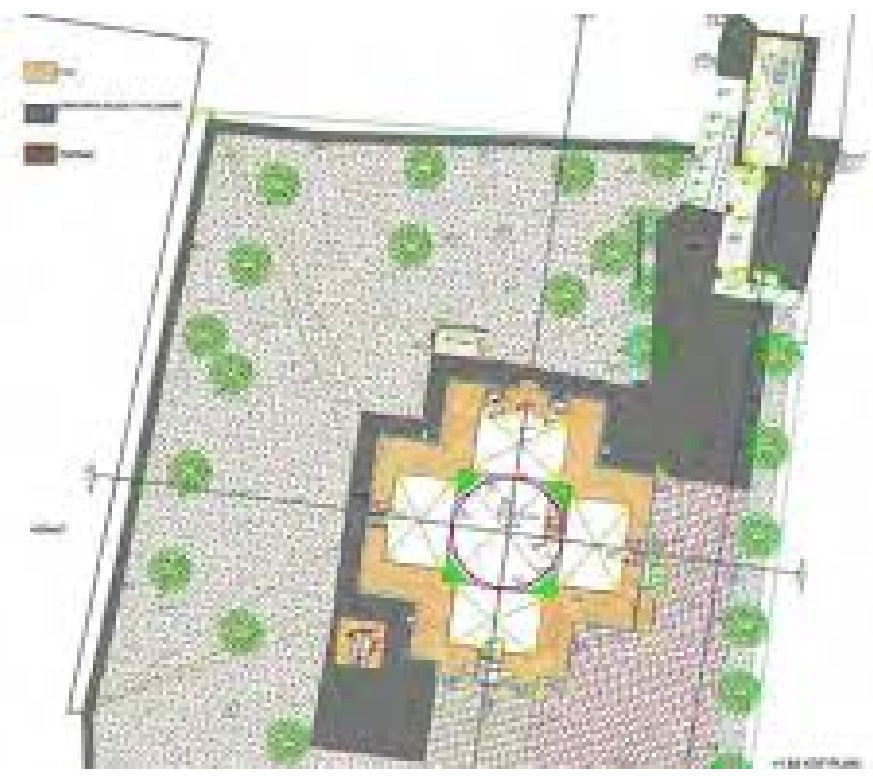

Şekil 3. Sultan Hamza-i Kebir Cami Planı (Yeşilbaş, 2014)

Caminin ana caddeye bakan giriş cephesi, kuzey cephesidir. Yapıya bir basamaklı merdivenle geçilmektedir. Caminin plan şemasına bakıldığında ortada kare bir mekânın dört yöne uzanan kollarının oluşturduğu haçvari bir çözüm görülmektedir. Ortadaki kare planı dıştan dilimli bir kubbe örtmektedir. Caminin doğu cephesinde kare kaide üzerine yükselen silindirik formda iki şerefeli minare mevcuttur. Yapının her cephesinde birer çörten bulunmaktadır (Yeşilbaş, 2014).

\subsection{Malzeme ve Strüktür Özellikleri}

Yapıda ana malzeme olarak kireç taşı kullanılmıştır. Kireçtaşının kullanımının insanlık tarihi kadar eski olduğu düşünülmektedir (Yüzer, 1997). Kireçtaşı dayanıklı ve uzun ömürlü olduğu için kiraçtaşının kullanıldığ1 yapılar günümüze kadar ulaşabilmektedir (Dinç, 2015). Tarih boyunca doğal taşlar kullanılarak inşa edilen yapılara günümüze ulaşan kültürel mirasların büyük bir kısmını oluşturmaktadır (Dal, Ergin ve Çelik, 2020a)

Kireçtaşı zamanla sıcaklık, basınç gibi etkenlere maruz kalarak değişime uğrar. Kireç taşında atmosferik etkilerin fazla olduğu yerlerde meydana gelen değişmeler daha farklı görülmektedir (Dal, 2010). Zamanla diş etkenler taşta bozunmalara neden olur ve yeterli önlem alınmazsa tahribat meydana getirebilir.

Yapıda taşıyıcı sistem olarak kalın duvarlarla birlikte kapı ve pencere açıklıklarında sivri kemer (Şekil 4), basık kemer (Şekil 5) ve düz atkılı kemer (Şekil 6) tercih edilmiştir. 

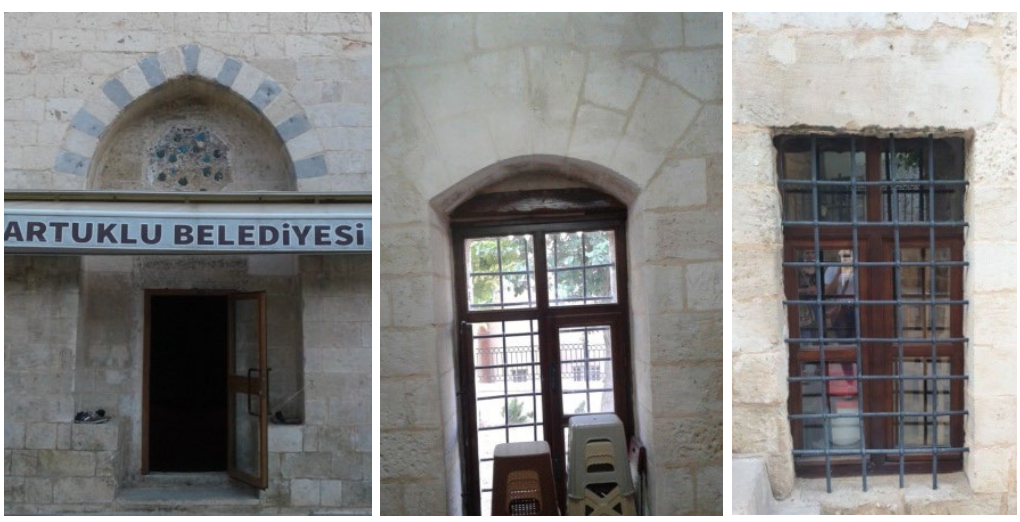

Şekil 4. Sivri Kemer

Şekil 5. Basık kemer

Şekil 6. Düz atkılı kemer

Mihrap yarım daire şeklinde bir girintisi olan ve çevresi duvara gömülmüş olan hafif sivri kemerle çevrelenmiştir. Mihrabın çevrelendiği kemer, siyah bazalt taşı ve sarı kalker taşın art arda sıralanmasıyla oluşan bir örgü tekniği ile örülmüştür (Yeşilbaş, 2014).

Kuzey cephesi, yapının ana caddeye bakan giriş cephesidir. Cephenin giriş kısmı dışa doğru taşırılmış ve sivri kemer kullanılmıştır. Sivri kemer gri bazalt taşı ve sarı kalker taşının art arda sıralanması ile oluşan bir sistemle örülmüştür (Şekil 7).

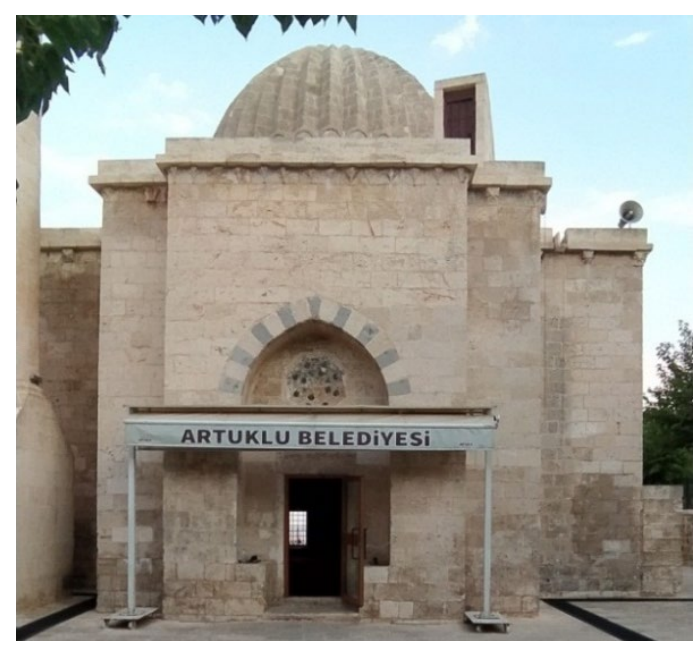

Şekil 7. Sultan Hamza-i Kebir Camii’nin kuzey cephesi

Yapının batı cephesi, sarımsı kalker taşla düzgün kesme taş tekniğiyle örülüdür. Cephede 9 basamaklı bir merdivenle çıkılan dikdörtgen kapı açıklı̆̆ı mevcuttur (Şekil 9). Daha önceden çekilen fotoğraflarda, yapıda merdivenin yer almadığı görülmektedir. Böylece merdivenin ve kapının sonradan eklenmiş olduğu anlaşılmaktadır (Yeşilbaş, 2014) (Şekil 8). 


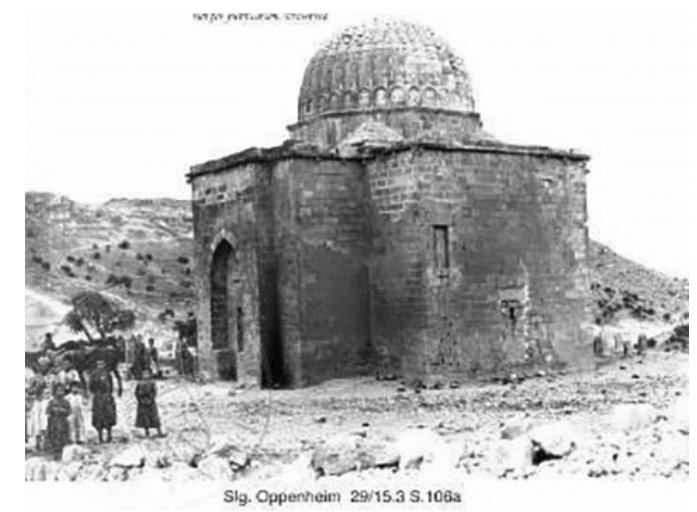

Şekil 8. Sultan Hamza-i Kebir Cami’nin batı cephesi (1939) (Yeşilbaş, 2014)

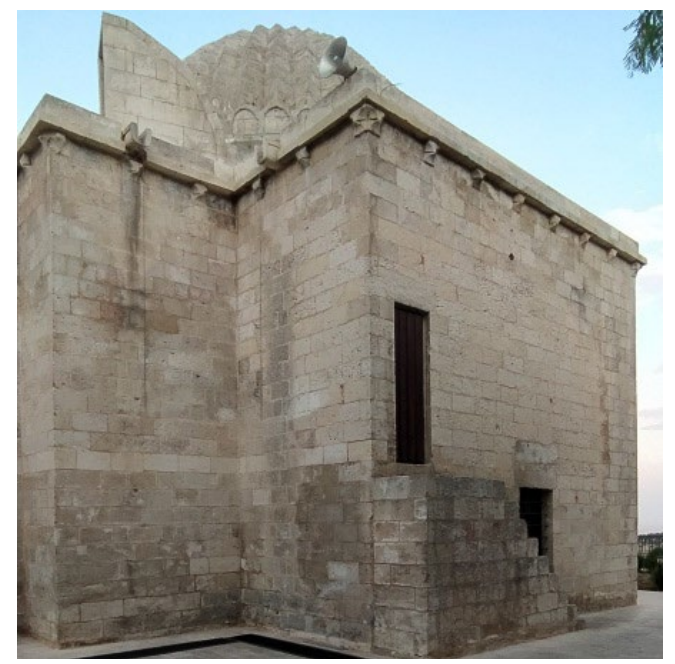

Şekil 9. Sultan Hamza-i Kebir Cami’nin batı cephesi

Yapının güney cephesi de diğer cephelerde olduğu gibi sarımsı kalker taşı düzgün kesme taş tekniğiyle örülüdür. Bu cephede kare formlu ve dilimli yarım kubbe ile şekillenmiş mihrap çıkıntısı (Şekil 10a) bulunmaktadır. Bu cephede düz atkı kemerli dikdörtgen formlu iki adet pencere vardır. Ayrıca cephede 1956-1960 yıllarında yapılmış mezar yapısı da yer alır (Yeşilbaş, 2014) (Şekil 10).

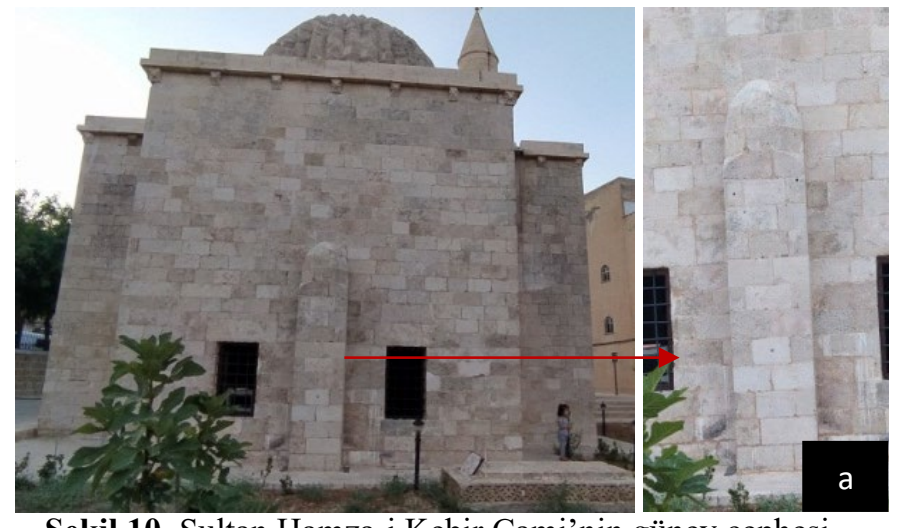

Şekil 10. Sultan Hamza-i Kebir Cami’nin güney cephesi

Doğu cephesi de diğer cephelerde uygulanan yöntemle inşa edilmiştir. Cephe sade görünümde olup sadece dikdörtgen formlu bir pencere açıklı̆̆ mevcuttur (Şekil 11). 

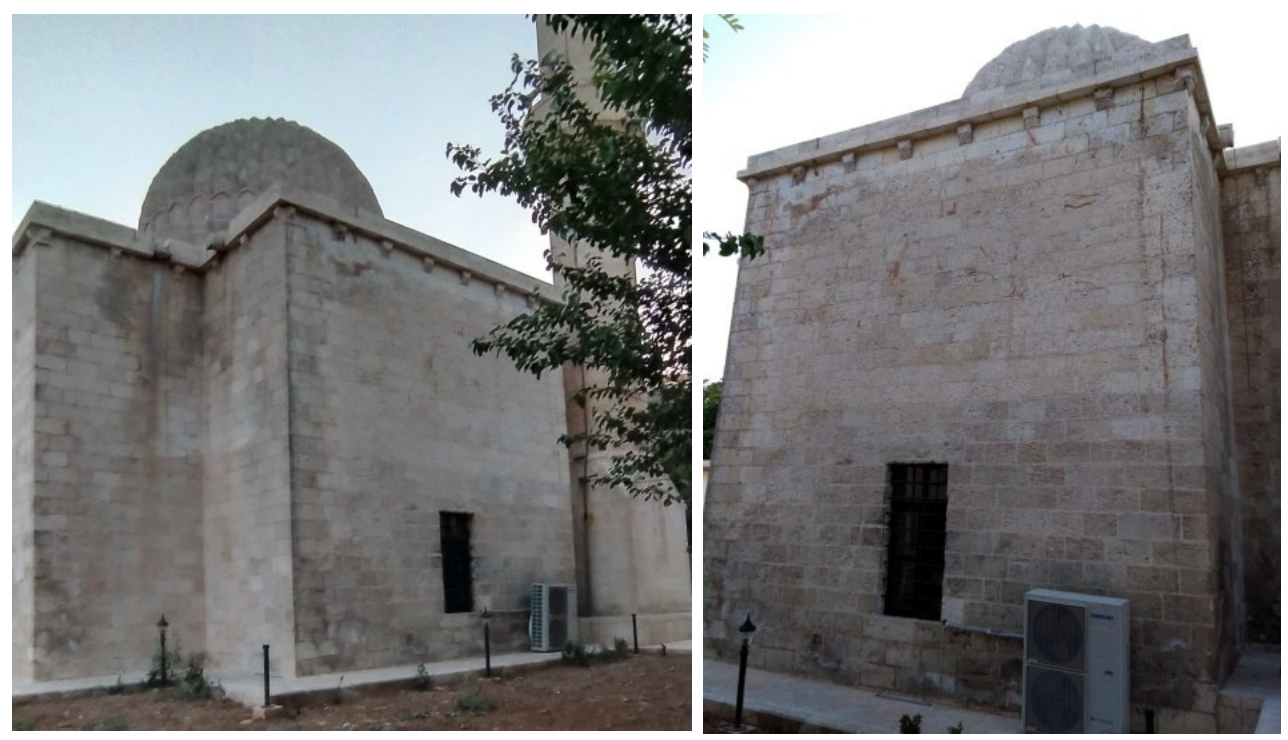

Şekil 11. Sultan Hamza-i Kebir Cami’nin doğu cephesi

Yapının kubbesi dış kısımdan sekizgen şekilli kasnağa binerken, iç kısımdan kubbeye geçişi trompla sağlanmıştır. Tromplar mukarnas süslemelerle donatılmıştır. Trompları saran sivri kemerler siyah ve sarı renkli kesme taşlarının art arda sıralanmasıyla oluşan almaşık teknikle tasarlanmıştır (Yeşilbaş, 2014).

İç mekân yapısında kare alanın oluştuğu hacın her bir kolunun köşe kısımları sütunlarla yumuşak geçiş sağlarken, kare alandan dört yana açılan kollar da beşik tonozlarla örtülmüştür (Şekil 12).
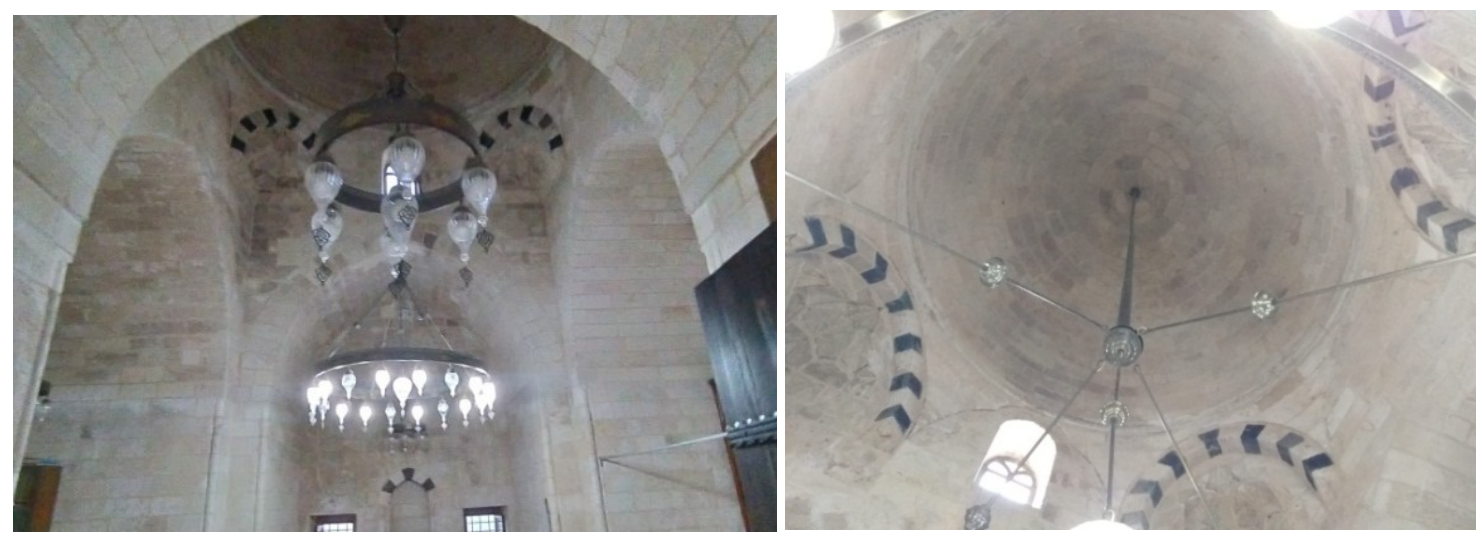

Şekil 12. Sultan Hamza-i Kebir Cami’nin iç görünüşü

\section{MARDIN İLİ MERKEZ İLÇESINDEKİ SULTAN HAMZA-İ KEBİR CAMISSINDE GÖRÜLEN TAŞ BOZUNMALARI}

Taştan yapılmış eserlerin bozunmalarına fiziksel, kimyasal ve biyolojik etmenler neden olurlar. Bu etmenler ayrı ayrı bozunmaya neden olduğu gibi birlikte de bozunma sürecini hızlandırırlar. Sultan Hamza-i Kebir Cami'nde zaman içinde bozunmalar meydana gelmiştir. Bu çalışmada bozunmalar dört başlıkta ele alınmıştır. Bunlar; fiziksel bozunmalar, kimyasal bozunmalar, biyolojik bozunmalar ve insan etkisi sonucunda meydana gelen bozunmalardır (Öcal, Dal, 2012).

\subsection{Fiziksel bozunmalar}

Sultan Hamza-i Kebir Cami'nde çeşitli etkenler sonucunda fiziksel bozunmalar meydana gelmiştir. İklimsel etkenler sonucu yapıda görülen malzeme kayıpları, Mardin'in gece-gündüz belirgin 1sı farkından dolayı meydana gelen çatlaklar, 
çok kullanımdan dolayı meydana gelen aşınma, derz boşalması, oyuklanma yapıda görülen hasarlardandır (Öztürk, 2017).

Çatlak oluşumu: Yapılarda genleşme, deprem, taşın çekme, basınç dayanımı gibi birçok sebepten dolayı, yapı elemanlarında kaymalar ve baskıdan kaynaklı çatlaklar meydana gelmektedir (Tintin, 2012). Camii'nin cephelerinde $(13 \mathrm{a}, 13 \mathrm{~b}, 13 \mathrm{c})$ ve iç mekanında (13d) çatlak oluşumuna rastlanmaktadır.
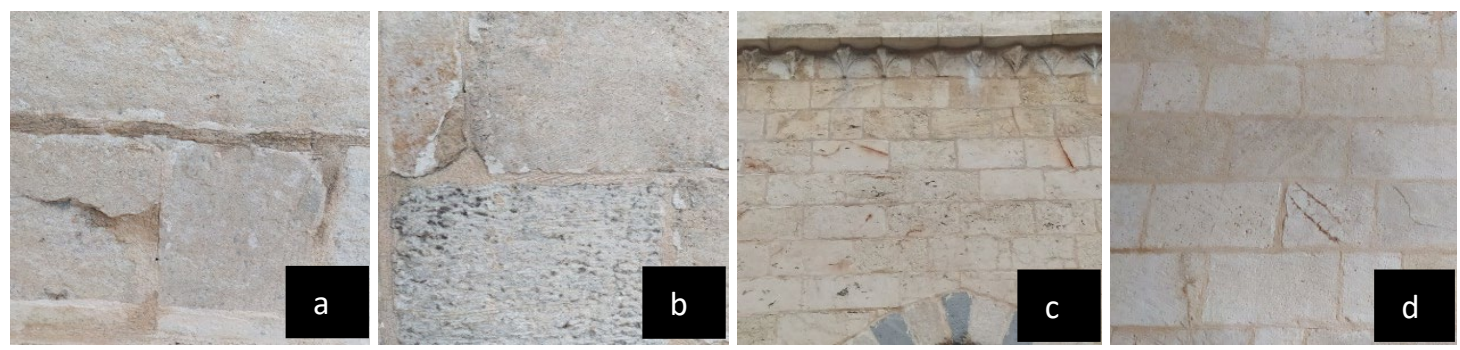

Şekil 13. Çatlak oluşumundan kaynaklı bozunmalar

Oyuklanma: Güneş, su, rüzgâr, sslanma kuruma gibi atmosfer etkileri nedeniyle iri tanelerin zayıflayarak yerinden çıkması olayına oyuklanma denir. Oyuklanma ile taşın yüzey alanı küçülür ve bozunma oranı arttı̆̆ için taşın yıpranma hızı artar (Karataş, 2018) Yapının tüm cephelerinde oyuklanma mevcuttur (Şekil 14).
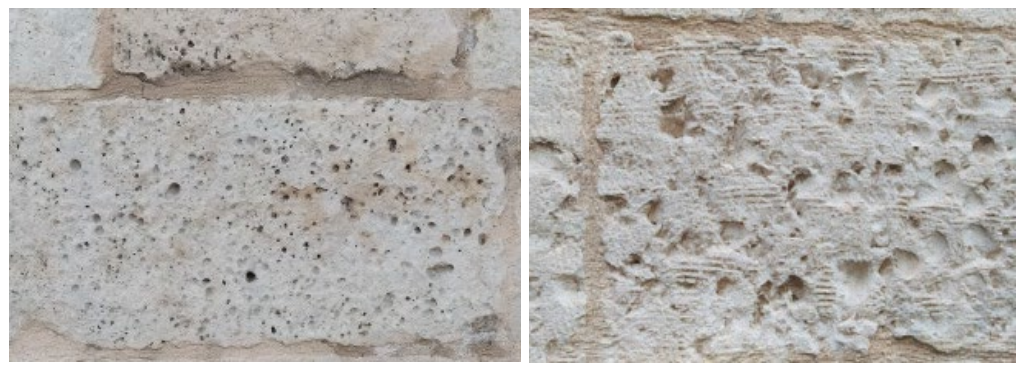

Şekil 14. Oyuklanma oluşumundan kaynaklı bozunmalar

Yüzey kaybı: Mardin'deki taş yapılarda genellikle kalker kullanılmıştır. İç nedenler ve su, rüzgâr, 1slanma-kuruma gibi dış etkenlerden dolayı taşın yüzeyi yıkanıp çözülmektedir. Çözünme ile birlikte taş yüzey zamanla aşınmaya uğrayıp yüzey kaybı oluşturmaktadır(Karataş, 2018). Yapının tüm cephelerinde yüzey kaybı oluşumu görülmüştür (Şekil 15).
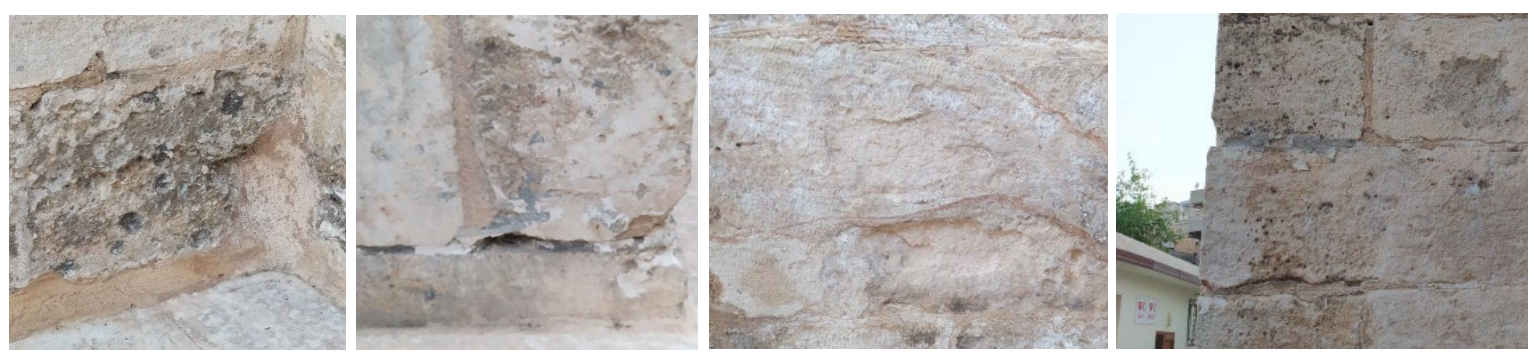

Şekil 15. Yüzey kaybı kaynaklı bozunmalar

Aşınma: Yapı elemanlarının sürtünmeye bağlı olarak zamanla kesitlerinin küçülmesi sonucu meydana gelen bir bozunma türüdür. Yapılarda taş yüzeylerinin kullanımından kaynaklı zarar görmesi ve suyun meydana getirdiği aşındırma gücü yüzey kayıplarının görülmesine neden olur (Tintin, 2012). Cami'de aşırı ziyaretçi akımı olan kapı eşiğinde (Şekil 16a) ve merdivende (Şekil 16b) aşınma meydana gelmiştir. 


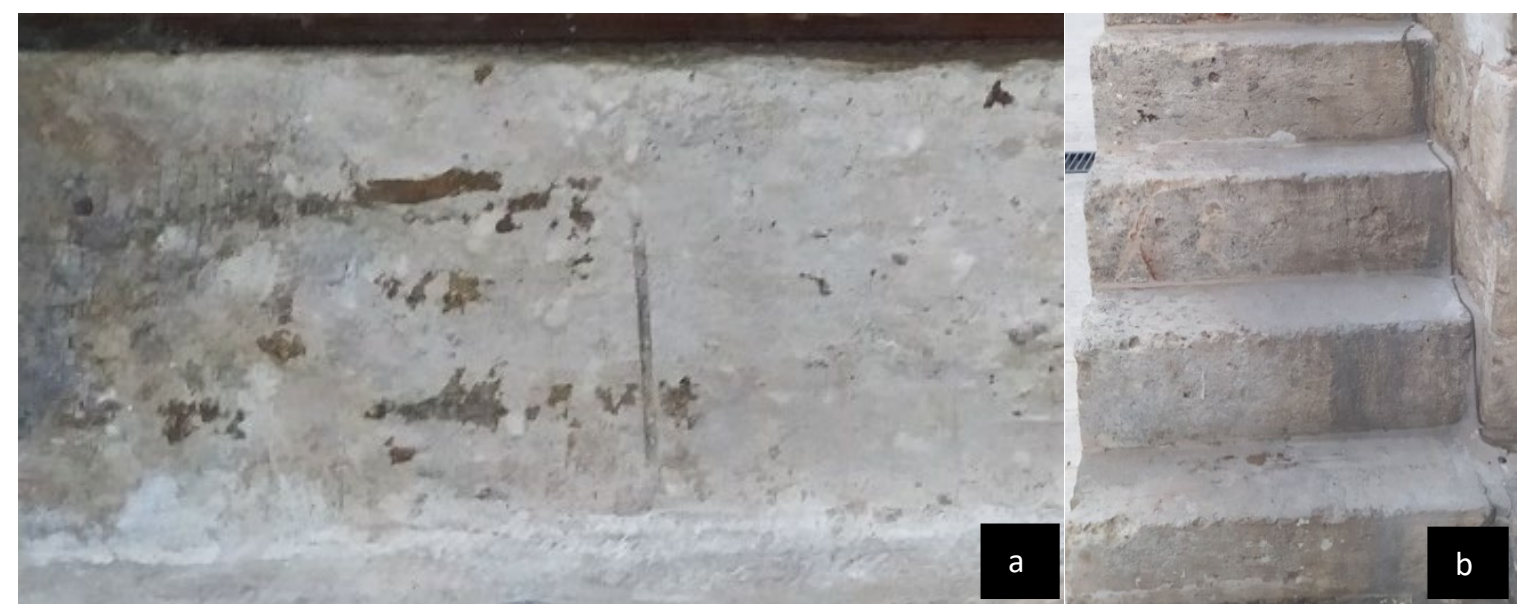

Şekil 16. Aşınma oluşumundan kaynaklı bozunmalar

Derz Boşalması: Taşlar duvar yapımında derz oluşturacak şekilde yerleştirilip harçla birleştirilirler. Fakat çeşitli nedenlerden dolayı zamanla özelliğini yitirip taşlardan ayrılma gösterebilirler.

Böylece taşlar arasındaki derzlerde farklı büyüklükte boşluklar ortaya çıkar. Yağmur ve kar suyunun iç yapıya daha kolay ulaşmasına neden olduğu için bozunmayı hızlandırır (Hasbay ve Hattap, 2017; Eskici ve vd., 2006). Cami'nin cephelerinde derz boşalmasına rastlanmaktadır (Şekil 17).
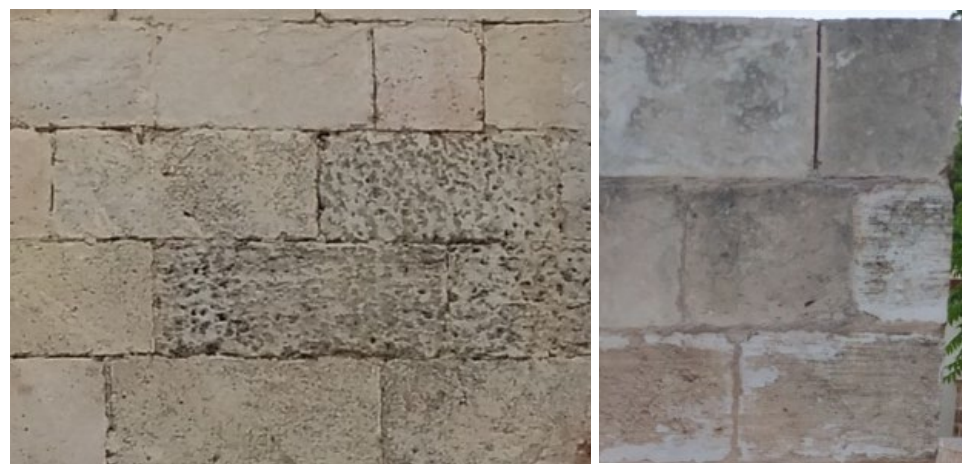

Şekil 17. Derz boşalması kaynaklı bozunmalar

\subsection{Kimyasal bozunmalar}

Genellikle atmosferik etkiler sonucu taşın kimyasal yapısında meydana gelen değişimlerdir (Dal ve vd., 2020b). Nem oranı, sıcaklık ve su kimyasal bozunmanın oluşumuna neden olan etkenlerdir. Sultan Hamza-i Kebir Cami'nde meydana gelen kimyasal bozunmalar; yüzey kirliliği, tuzlanma ve renk değişimidir.

Yüzey kirliliği: Genellikle hava kirliliğinin neden olduğu gri renkli ve yüzeyde ince tabaka halinde görülen oluşumlardır. Taşın cinsine ve kirliliğe neden olan kaynağa göre; kirin rengi ve yapısı değişebilir (Karataş, 2018; MEB, 2013). Cami'de tromplarda (Şekil 18a) ve giriş kapısının üst kısmında (Şekil 18b) yüzey kirliliğine rastlanmaktadır. 


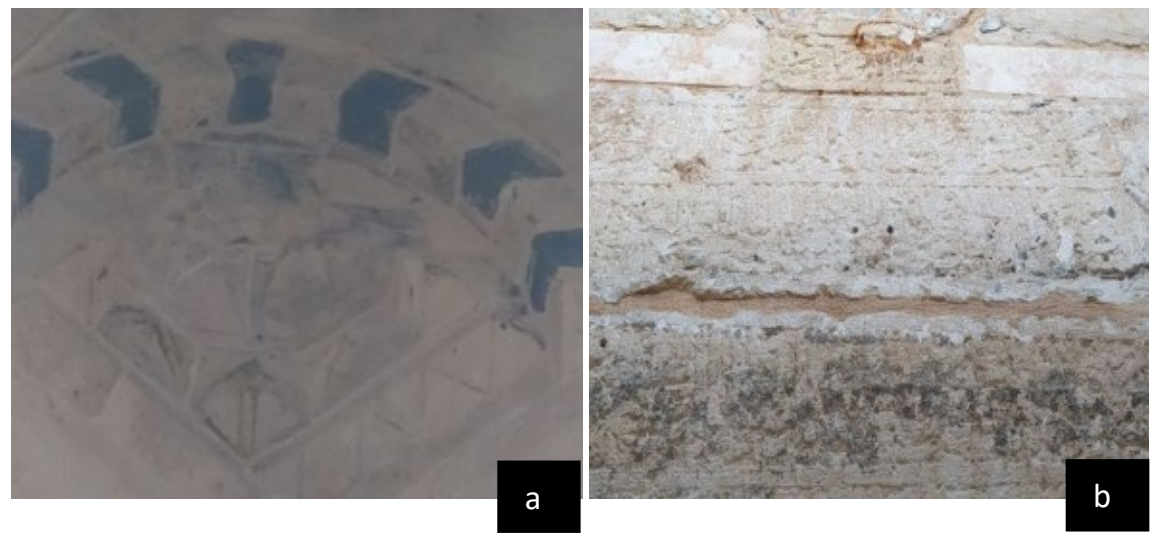

Şekil 18. Yüzey kirliliği oluşumu kaynaklı bozunmalar

Tuzlanma: Kapiler etkiler ile duvar yüzeyinde yükselen su buharlaşırken içinde bulunan tuzlar kristalleşip malzeme boşluklarında ve sıva yüzeylerinde birikip tuz kusmalarına yol açarlar. Zamanla kristaleşen tuzlar basınç artışının görülmesiyle malzeme ve sıva patlamasında rol oynarlar (Tintin, 2012). Cami’nin cephelerinde (Şekil 19b, Şekil 19d) ve iç mekânında (Şekil 19a, Şekil 19b, Şekil 19d) tuzlanma mevcuttur. Cephede özellikle çörtenlerin olduğu kısımda (Şekil 19a) daha sık gözlemlenmektedir.
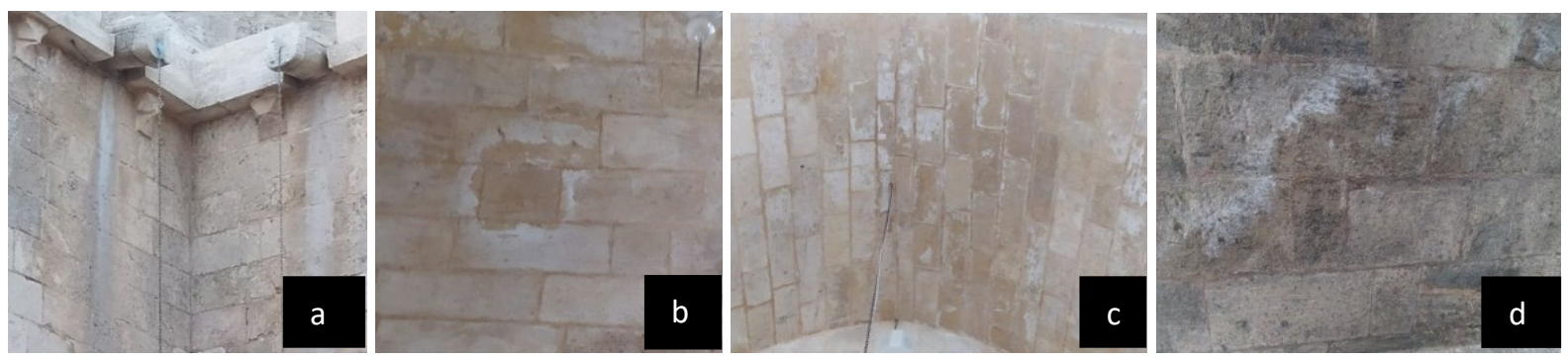

Şekil 19. Sultan Hamza-i Kebir Camii’nde tuzlanma oluşumu kaynaklı bozunmalar

Renk Değişimi: Gün ışığı, UV (ultraviyole) ışınları, su, nem gibi etkilerle taşın esas renginin değişime uğrayarak renginin değiştirmesi ya da renginin açılması sonucu meydana gelen bozunma türüdür (MEB, 2013; Öcal ve Dal, 2012). Yapının minaresinde (Şekil 20a), merdiven duvarında (Şekil 20b) ve cephelerinde (Şekil 20c, Şekil 20d) renk değişiminin meydana geldiği gözlenmiştir.
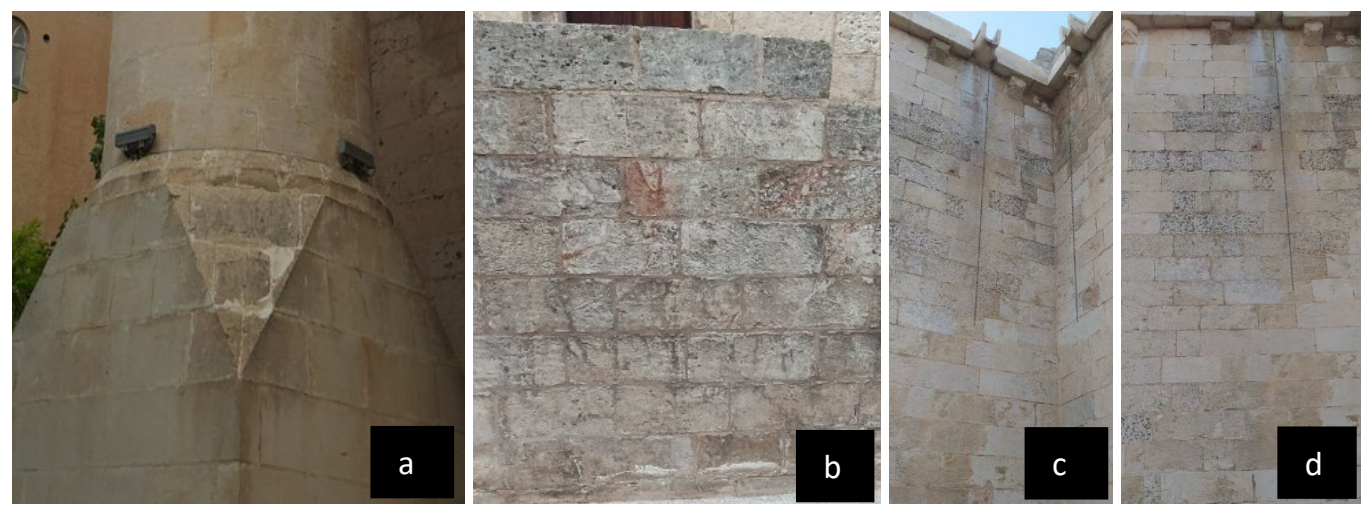

Şekil 20. Renk değişimi kaynaklı bozunmalar

\subsection{Biyolojik bozunmalar}

Taştan yapılmış yapıların bozunmasına neden olan etmenlerden biri de canlı organizmalardır. Yapıdaki biyolojik bozunmalar gözlemlendiğinde, bitki oluşumu (Şekil 21) ve mikroorganizma oluşumları (Şekil 22) görülür. 

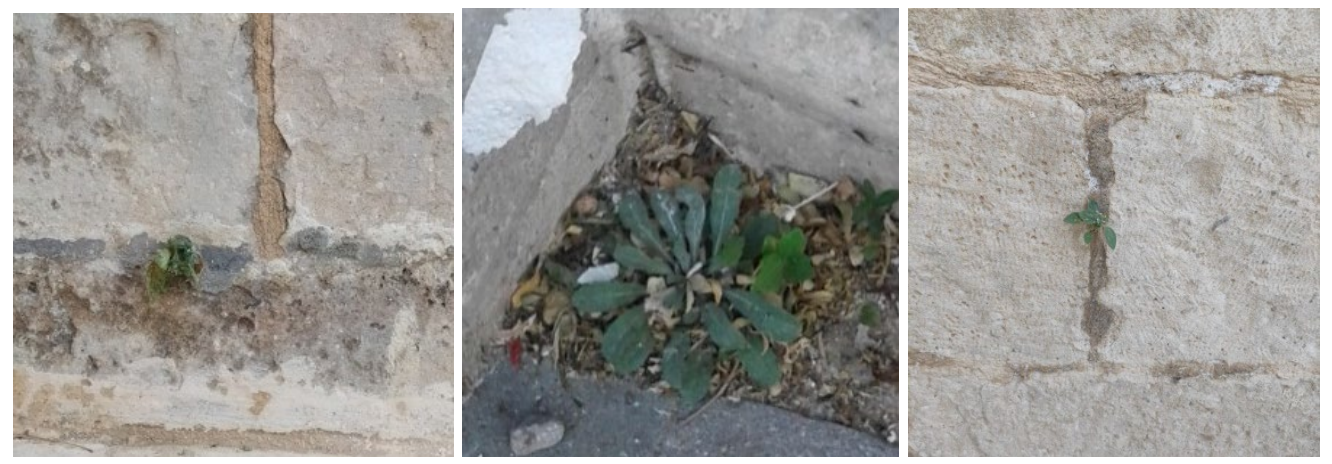

Şekil 21. Bitki oluşumu kaynaklı bozunmalar
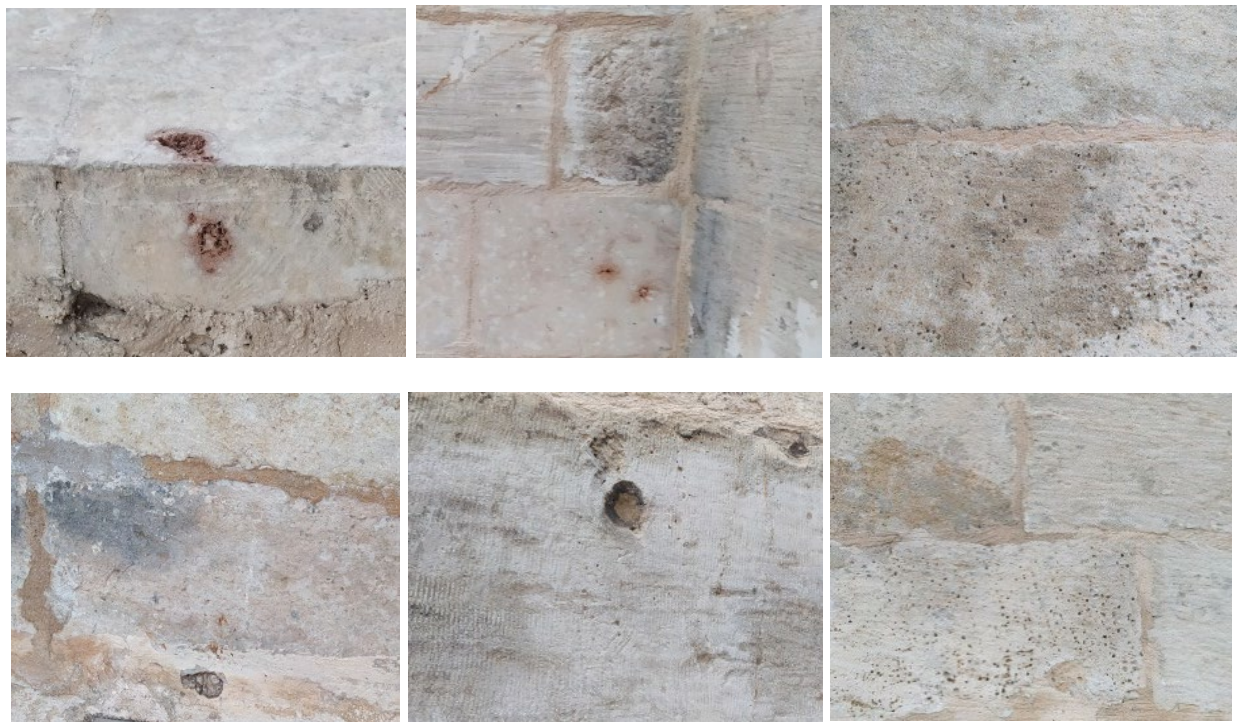

Şekil 22. Mikroorganizma oluşumu kaynaklı bozunmalar

\section{4. İnsan etkileri ile olan bozunmalar}

Tarihi yapıların bozunmasına neden olan faktörlerden biri de insanlardır. Kötü kullanım, hatalı onarım, bakımsızlık gibi çeşitli şekillerde yapılarda ve malzemelerde bozunmalara neden olmaktadır (MEB, 2013; Dal ve vd., 2016). Camii'de yanlış malzeme seçimi (Şekil 23a), hatalı onarım örneklerinden biri çimento harcıyla onarım (Şekil 22b, Şekil 23c, Şekil 23d, Şekil 23e, Şekil 231), hatalı restorasyon uygulamalarından kaynaklı bozunmaların (Şekil 23f, Şekil 23g, Şekil 23h) olduğu gözlemlenmiştir. 

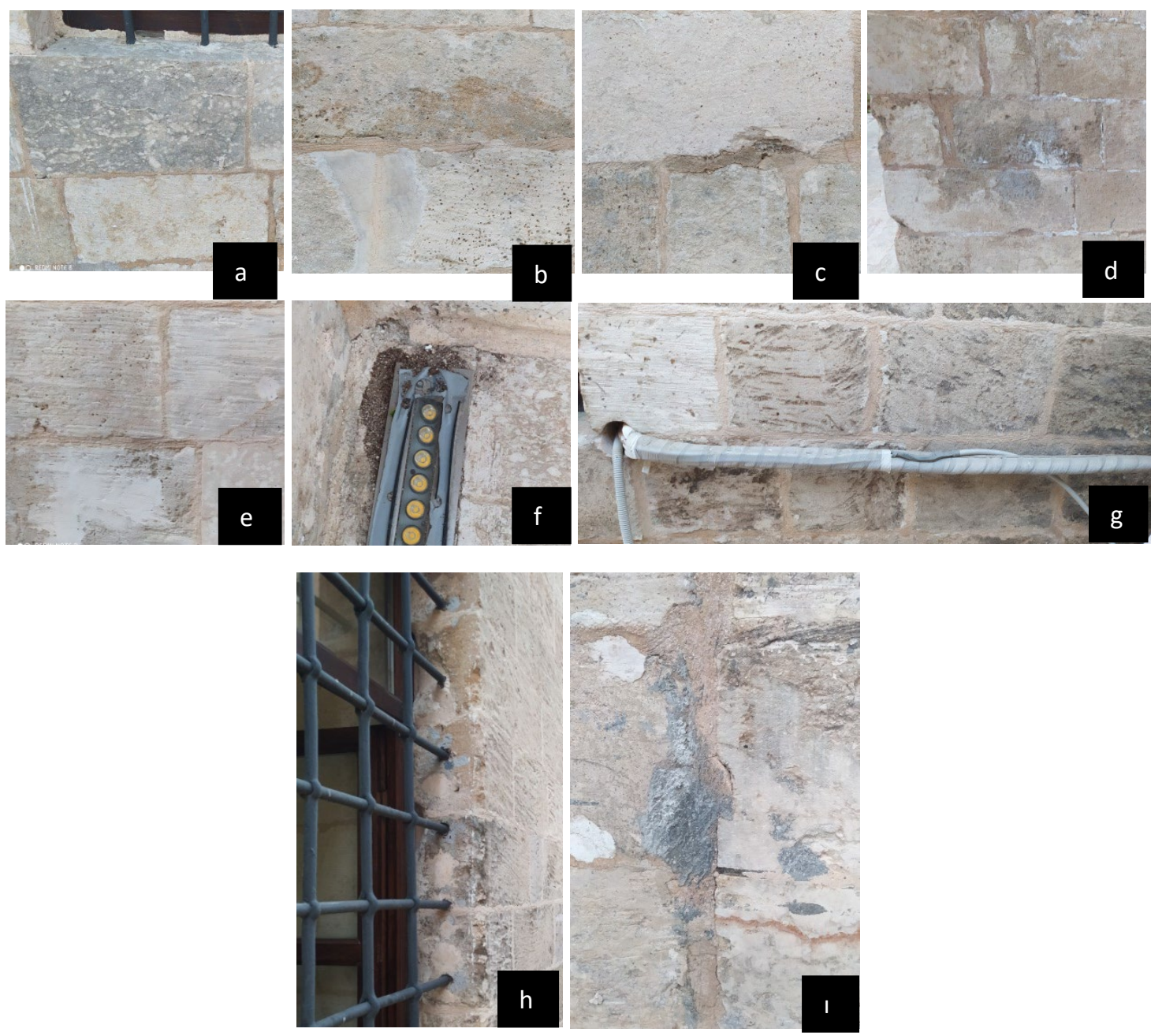

Şekil 23. İnsan etkileri kaynaklı bozunmalar

\section{SONUÇ:}

Sultan Hamza-i Kebir Cami, Mardin ilinde bulunan kültürel miraslarımızdan biridir. Bu çalışmada Sultan Hamza-i Kebir Cami'nin bozunmaları fiziksel, kimyasal, biyolojik ve insan etkisi sebebiyle meydana gelen bozunmalar olarak dört başlıkta ele alınmıştır. Yapıda fiziksel bozunma olarak çatlak-kırık oluşumu, oyuklanma, yüzey kaybı, aşınma ve derz boşalmaları meydana gelmiştir. Kimyasal bozunma olarak yüzey kirliliği, tuzlanma ve renk değişimi görülmüştür. Mikroorganizmaların taşa yerleşmesi ve bitki oluşumu sonucunda biyolojik bozunma ve insan etkisi sonucunda meydana gelen hatalı onarımlar da mevcuttur.

Caminin tüm cephelerine bakıldığında; kuzey ve doğu cephelerinde kimyasal bozunma, güney ve batı cephelerinde ise fiziksel bozunma daha fazla görülmektedir. Biyolojik bozunmanın en çok görüldüğü cephe güney cephesi olurken, insan kaynaklı bozunmanın en çok görüldüğü cephe ise doğu cephesidir.

Bazı bozunma türleri başka bir bozunmaya zemin hazırlayarak deformasyonları hızlandırabilmektedir. Bu nedenle oluşan bozunmaların zamanında müdahale edilerek çözümlenmesi, hasarların büyümesine engel olacaktır. Aksi takdirde yapıda görülen bu mevcut bozunma ve deformasyonların zaman içerisinde artması durumunda taşıyıcı sistemde de hasar (çatlak, ezilme vb.) artışları meydana gelecektir. Yapısal sorunların artmasına ve yapının kullanılamaz duruma gelmesine engel olmak için, tespit edilen sorunlara karşı çözüm önerilerinin geliştirilmesi, çevresel faktörlere karşı etkili ve koruyucu önlemler alınması önerilmektedir. 
Sultan Hamza-i Kebir Cami Mardin ilindeki önemli kültürel miraslarımızdan biridir. Çevresel faktörlere maruz kalan ve hasar oluşumları gözlenen bu yapıda meydana gelen bozunmaların tespiti, yapının korunabilmesindeki ilk adımdır. $\mathrm{Bu}$ tespitler, mevcut problemlerin çözülmesi ve hasar oluşumlarının büyümeden önlenebilmesi açısından yol göstericidir. Yapıda hasarlara karşı gerekli önlemler alınmadığında, yapı zamanla tahrip olup işlevselliğini kaybedecektir. Kültürel miras niteliğindeki bu yapıda meydana gelen bozunmalara neden olan etkenlere karşı alınacak önlemler, yapının özgünlüğünün korunarak sağlanarak sonraki nesillere aktarılması açısından gereklidir.

\section{Etik Standart ile Uyumluluk}

Çıkar Çatışması: Yazarlar herhangi bir çıkar çatışmasının olmadığını beyan eder.

Etik Kurul İzni: Bu çalışma için etik kurul iznine gerek yoktur.

Teşekkür: Yoktur.

\section{KAYNAKÇA:}

Alioğlu, F., 2000. Mardin Şehir Dokusu ve Evler, Tarih Vakfı Yayınlar, İstanbul

Dal, M., 2010. Trakya Bölgesi Tarihi Yapılarında Kullanılan Karbonatlı Taşların Bozulma Nedenleri, Vakıflar Dergisi, Adana

Dal, M., Ergin, Ş. Çelik, A.B., 2020a. Abdullatif Camii (Latifiye Camii) Taş Bozunmalarının Tesbiti ve XRF Spektrometresi ile Kimyasal Analizi, Mimarlık Üzerine-1, 80-102, Mardin

Dal, M., Ergin, Ş. Çelik, A.B., 2020b. Şeyh Çabuk Camii Cephelerinde Görülen Taş Bozunma Sorunlarının İrdelenmesi ve Kimyasal Analizlerinin Karşılaştırılması, Mimarlık Üzerine-1, 103-124, Mardin

Dal, M., Yalçın, M., Öcal, A. Ad., 2016 Gazimağusa Kale içindeki Tarihi Taş Yapılarda Görülen Bozunmalar, Çukurova Üniversitesi Mühendislik Mimarlık Fakültesi Dergisi, Adana

Dinç, E., 2015. Geleneksel Mardin Mimarisinde Kullanılan Malzeme ve Uygulanan Yapım Tekniklerinin Günümüz Restorasyon Uygulamalarında Sürdürülebilirliğinin İncelenmesi, Yüksek Lisans Tezi, Dicle Üniversitesi, Diyarbakır.

Eskici, B., Akyol, A. A., Kadığlu, Y. K., 2006. Erzurum Yakutiye Medresesi Yapı Malzemeleri, Bozulmalar ve Koruma Problemleri, Ankara Üniversitesi Dil ve Tarih-Coğrafya Fakültesi Dergisi 46, 165-188

Hasbay, U. Hattap, S., 2017. Doğal Taşlardaki Bozunma (Ayrışma) Türleri ve Nedenleri, Bilim ve Gençlik Dergisi, $5(1)$.

Karagülle, C., 2009. Yerel Verilerin Konut Tasarım Sürecinde Değerlendirilmesi: Mardin Örneği, Doktora Tezi, İTÜ, İstanbul

Karataş, L., 2018. Mardin Kenti İbadet Yapılarında Malzeme Kullanımı ve Sorunları Üzerine Bir Araştırma, Yüksek Lisans Tezi, Uludağ Üniversitesi, Bursa

Kaya, K., 2015. Geleneksel Konutlarda Kullanıcı Memnuniyetinin Tespit Edilmesi: Mardin Örneği, Electornic International Journal of Education, Arts and Science, 1(2), 241-263, USA

MEB, 2013. Taş Bozunmalarını Teşhis Etme, İnşaat Teknolojisi, Ankara

Öcal, A. D., Dal, M., 2012. Doğal Taşlardaki Bozunmalar, Mimarlık Vakfı İktisadi İşletmesi, İstanbul

Öztürk, S., 2017. Geleneksel Konut Cephelerindeki Bozulma ve Hasar Nedenlerinin İrdelenmesi: Antalya-Kaleiçi Örneği,Yüksek Lisans Tezi, Gebze Teknik Üniversitesi, Gebze

Tintin, Z., 2012. Arkeolojik Alanda Taş Koruma Sağlamlaştırma Yöntemleri Kültür ve Turizm Bakanlığ1 Ankara Anadolu Medeniyetler Müzesi Müdürlüğü Uzmanlık Tezi, Ankara 
Uyar, S., 2019. Mardin’in Kutsal Mekan ve Ritüelleri, lisans tezi, AÜ., Mardin

Yeşilbaş, E., 2014. Mardin'de Hamza-i Kebir Türbesi Üzerine Yeni Değerlendirmeler, İnanç, Kültür ve mitoloji araştırmaları dergisi, Milel ve Nihal, 11 (2), 163-182., Mardin.

Yüzer, E., 1997. Türkiye’nin Doğal Taşları, Gün Matbaası, İstanbul

Url1,2020.https://www.google.com.tr/search?q=mardin\%27in+konumu\&sxsrf=ALeKk00t0TcMlx47bDpsZU90wI3eI L-

x8Q:1595621678363\&source $=\operatorname{lnms} \& \mathrm{tbm}=$ isch\&sa $=X \& v e d=2$ ahUKEwiMtdb62ebqAhVSRBoKHVX4Bz4Q_AUoA3 oECA8QBQ\&biw=1366\&bih=657, Erişim tarihi:20.07.2020

Ur12,2020 https://kulturenvanteri.com/yer/hamza-i-kebir-camii mardin/\#16/37.316395/40.750954 